4 Federico Lopez-Moya ${ }^{1}$, Magdalena Martin-Urdiroz ${ }^{2}$, Miriam Oses-Ruiz ${ }^{3}$, Mark D.

5 Fricker $^{4}$, George R. Littlejohn $^{2,5}$, Luis V. Lopez-Llorca ${ }^{1}$ and Nicholas J. Talbot ${ }^{3}$

6

7

8

\section{Chitosan inhibits septin-mediated plant infection by the rice blast fungus Magnaporthe oryzae in a Protein Kinase C and Nox1 NADPH oxidase-dependent manner}

${ }^{1}$ Laboratory of Plant Pathology, Department of Marine Sciences and Applied Biology, University of Alicante, Alicante, Spain

${ }^{2}$ School of Biosciences, University of Exeter, Exeter EX4 4QD, United Kingdom

${ }^{3}$ The Sainsbury Laboratory, University of East Anglia, Norwich Research Park, Norwich NR4 7UH, United Kingdom

${ }^{4}$ Department of Plant Science, University of Oxford, South Parks Road, Oxford, OX1 3RB, United Kingdom

${ }^{5}$ School of Biological and Marine Sciences, Plymouth University, Portland Square Building Room A404, Drake Circus, Plymouth, PL4 8AA, United Kingdom

(1)




\section{Summary}

- Chitosan is a partially deacetylated linear polysaccharide composed of $\beta-1,4-$ linked units of D-glucosamine and $\mathrm{N}$-acetyl glucosamine. As well as acting as a structural component of fungal cell walls, chitosan can be applied as a potent antifungal agent. However, the mode-of-action of chitosan in fungal pathogens is poorly understood.

- Here, we report that chitosan is effective for control of rice blast disease. Chitosan application impairs growth of the blast fungus Magnaporthe oryzae and has a pronounced effect on appressorium-mediated plant infection. Chitosan inhibits septin-mediated F-actin re-modelling at the appressorium pore, thereby preventing re-polarisation of the infection cell and rice leaf cuticle penetration.

- We found that chitosan causes plasma membrane permeabilization of M. oryzae and affects NADPH oxidase-dependent synthesis of reactive oxygen species, essential for septin ring formation and fungal pathogenicity. Our data further show that the toxicity of chitosan to $M$. oryzae requires the protein kinase $\mathrm{C}$ dependent cell wall integrity pathway and the Nox1 NADPH oxidase. A conditionally lethal, analogue (PP1)-sensitive mutant of $\mathrm{Pkc1}$ is partially remediated for growth in the presence of chitosan and PP1, while $\Delta$ noxl mutants increase their glucan/chitin cell wall ratio, rendering them resistant to chitosan.

- Taken together, our data show that chitosan is a potent fungicide for control of the rice blast fungus which involves the cell wall integrity pathway, disrupts plasma membrane and inhibits septin-mediated plant infection.

KEY WORDS: actin, chitosan, $M$. oryzae, membrane permeabilization, NADPH oxidase, pathogenicity, Pkc1 pathway, ROS, septin. 
2 Plant pathogenic fungi are responsible for many of the world's most serious crop 3

\section{Introduction} diseases and yet remain very challenging to control (Fisher et al., 2012; Fisher et al. 2018). Fungicide application is often not completely effective, has environmental consequences and resistance to fungicides occurs very frequently (Lucas et al., 2015). Chitosan is a biopolymer obtained by partial N-deacetylation of the $\beta$-1,4-D-linked polymer of $\mathrm{N}$-acetyl glucosamine, chitin (Kumar, 2000). As well as being a structural component of fungal cell walls, chitosan also displays anti-microbial activity (Allan \& Hadwiger, 1979). Chitosan has a $\mathrm{pK}_{\mathrm{a}}$ value of $\sim 6.3$ and it is cationic at lower $\mathrm{pH}$ values, due to protonation of its amino groups. Chitosan inhibits the growth of filamentous fungal plant pathogens, such as Botrytis cinerea (Muñoz \& Moret, 2010) and Fusarium oxysporum (Palma-Guerrero et al., 2008; Al-Hetar et al., 2010). Chitosan therefore shows considerable potential as a naturally occurring, novel antifungal agent, but its precise mode of action in plant pathogenic fungi remains unclear.

Chitosan inhibits the growth of sensitive fungi, causing massive membrane permeabilization (Palma-Guerrero et al., 2009; Palma-Guerrero et al., 2010). In Neurospora crassa, chitosan exposure causes generation of an oxidative response, which leads to membrane permeabilization and cell death (Lopez-Moya et al., 2015). Recent studies, however, have also demonstrated that cell wall composition plays a key role in fungal sensitivity to chitosan (Aranda-Martinez et al., 2016) as well as mitochondrial activity (Jaime et al., 2012). Transcriptional profiling studies meanwhile have revealed that cytoskeletal functions are also compromised by chitosan exposure in $N$. crassa. Genes related to actin polymerisation in $N$. crassa, for example, are repressed by chitosan treatment (Lopez-Moya, et al., 2016), suggesting that actindependent functions, such as cell polarity, exocytosis, endocytosis, cytokinesis, and organelle movement (Barja et al., 1993, Berepiki et al., 2010) may be affected by chitosan exposure. In all of these reports, however, it is unclear whether the observations reveal the mode-of-action of chitosan, or rather the pleiotropic effects it has on cell viability. It is therefore vital to carry out more comprehensive investigations of the manner in which chitosan affects fungal viability, in order to determine its likely efficacy as a novel fungicide. 
1 In this report, we describe a series of experiments designed to determine the mode-ofaction of chitosan in the control of a major crop disease-causing fungus, Magnaporthe oryzae, which has a global impact on food security (Castroagudin et al., 2015; Zhang et al., 2009; Wilson \& Talbot, 2009). Magnaporthe oryzae is the causal agent of rice blast disease and is responsible for up to $30 \%$ losses to the annual rice harvest (Talbot, 2003). M. oryzae infects rice cells by using specialised infection structures called appressoria. These structures generate enormous turgor, which is applied as physical force to penetrate epidermal cells and then infect rice tissues (Wilson \& Talbot, 2009). The dome-shaped appressorium possesses a thick melanin layer in its cell wall, which is critical for infection (Chumley \& Valent, 1990) and can generate up to 8.0 MPa of pressure (Howard et al., 1991; Howard \& Valent, 1996), by accumulating molar concentrations of glycerol and other polyols as compatible solutes (de Jong et al., 1997). Appressorium turgor is sensed by the $\operatorname{Sln} 1$ histidine-aspartate kinase, which acts via the Protein kinase C-dependent cell wall integrity pathway and the cAMPdependent protein kinase A pathway in order to modulate glycerol accumulation and melanin biosynthesis, once a critical threshold of pressure has been reached. An NADPH oxidase-dependent regulated burst of reactive oxygen species (ROS) then occurs, which leads to septin-dependent re-polarisation of the appressorium and plant infection (Ryder et al., 2019). ROS generation requires NADPH oxidases encoded by the NOX1, NOX2 and NOXR genes, which are all essential for M. oryzae infection (Egan et al., 2007; Ryder et al., 2013). In other fungi, NADPH oxidase-dependent ROS generation is also known to play roles in cell polarity and invasive growth. In Sordaria macrospora, for instance, Nox1 regulates gene expression involved in cytoskeleton remodelling, hyphal fusion and mitochondrial respiration (Dirschnabel et al., 2014), while in the endophytic fungus Epichloë festucae NOXA, is essential for polarized growth and hyphal fusion (Eaton et al., 2011). In M. oryzae, NOX1, is also involved in cell wall organisation and $\Delta$ noxl mutants is resistant to many cell wall perturbing agents, such as calcofluor white (Egan et al., 2007). This role may be conserved in fungi, because in the mycoparasitic fungus Coniothyrium minitans, for example, CmNOX1 and CmSLT2, regulate localisation of the cell wall integrity-associated MAP kinase (MAPK) and mediate changes in fungal gene expression associated with cell wall integrity (Wei et al., 2016). 
1 The Nox2-regulated synthesis of ROS is necessary for recruitment and organisation of

2 four septin guanine nucleotide-binding proteins to the appressorium pore (Ryder et al.,

3 2013), where they form a hetero-oligomeric ring complex, essential for re-polarisation

4 of the appressorium (Dagdas et al. 2012). The septin ring rigidifies the cortex of the

5 appressorium, acting as a scaffold for F-actin organisation. Septins also act as a lateral

6 diffusion barrier, required for localisation of polarity determinants such as Chm1 (Li et

7 al. 2004), Tea1 and Las17 (Dagdas et al., 2012).

8 In this study, we set out to determine the effect of exposure to chitosan on infection-

9 related development by $M$. oryzae. Chitosan is known to be a cell wall (CW) component in $M$. oryzae, which is important in adhesion and appressorium formation (Geoghegan \& Gurr, 2016). We were interested in whether exposure to exogenous chitosan was, however, toxic to the fungus, as shown for other fungi and, if so, how it might be acting on the cellular events necessary for plant infection. We provide evidence that chitosan exposure is fungicidal to $M$. oryzae. causing membrane permeabilization and preventing plant infection. Importantly, we also show that the cell wall integrity pathway and Nox1 NADPH oxidase activity are both essential for the toxicity of chitosan, providing insight into its mode of action.

\section{Material and Methods}

\section{Fungal strains and growth conditions}

The wild-type strain of Magnaporthe oryzae, Guy11 (Leung et al., 1988) and transgenic rice blast isolates expressing Sep4-GFP::H1-RFP, Sep5-GFP, Gelsolin-GFP, Chm1-GFP, Tea1-GFP and Grx1-roGFP2 strains were stored in the laboratory of NJT. Gene replacement mutants $\Delta$ noxl, $\Delta$ nox2, $\Delta$ noxlnox2, $\Delta m p s 1$ and the $p k c 1^{A S}$ were generated as described previously (Xu et al., 1998; Ryder et al., 2013; Penn et $a l ., 2015)$. All fungal strains were grown on complete medium (CM) at $24^{\circ} \mathrm{C}$ under a 12h light/dark photoperiod (Talbot et al., 1993). Conidial suspensions were obtained in sterile distilled water (SDW) by scraping the surface of 12-day-old plate cultures with a spreader, before being filtered through Miracloth (Calbiochem, USA) and concentrated by centrifugation $(13,000 \mathrm{rpm}, 1 \mathrm{~min})$. 


\section{Preparation of Chitosan}

2 Medium molecular weight chitosan $(70 \mathrm{kDa})$ with an $85 \%$ deacetylation degree (T8) 3 was provided by Marine BioProducts $\mathrm{GmbH}$ (Bremerhaven, Germany). Chitosan 4 solutions were prepared as described by Palma-Guerrero et al. (2008). The resulting solution was dialysed against distilled water and autoclaved. Chitosan solutions were stored at $4{ }^{\circ} \mathrm{C}$ until used, and never stored for longer than 30 days.

\section{Exposure of M. oryzae to chitosan during plant infection}

To evaluate the effect of chitosan on the pathogenicity of $M$. oryzae, leaf spot and spray infection assays were performed. Conidia of Guy11 were collected and suspensions adjusted to $10^{5}$ conidia $\mathrm{ml}^{-1}$. Leaf spot bioassays were performed by inoculating $20 \mu \mathrm{l}$ droplets of $1 \times 10^{5}$ conidia $\mathrm{ml}^{-1}$ onto the adaxial surfaces of detached rice leaves of the blast-susceptible dwarf Indica variety of rice CO-39 (Talbot et al., 1993) using 4 replicate leaves per treatment. Inoculated rice leaves were incubated in moist chambers and after $5 \mathrm{~d}$, the size of the resulting rice blast disease lesion recorded. Treatments included a control experiment (no chitosan) and conidial suspensions containing either 1 or $5 \mathrm{mg} \mathrm{ml}^{-1}$ chitosan, respectively. For leaf spray bioassays, CO-39 rice plants at the three-leaf stage (normally, 21-days-old) were sprayed with $5 \mathrm{ml}$ of a suspension of $5 \times 10^{4}$ conidia $\mathrm{ml}^{-1}$ using an artist's airbrush (Badger Air-Brush Co, Franklin, IL, USA). Plants were also sprayed with chitosan only (no conidia) and all experiments repeated three times. Inoculated plants were placed in plastic bags for 2 days to achieve high humidity and symptoms scored after 5 days. Leaves were collected and rice blast lesions quantified.

\section{Leaf sheath bioassays}

Leaf sheath fragments $(2-3 \mathrm{~cm}$ long) were obtained from 21-day-old seedlings of rice cultivar CO-39. Leaf sections were inoculated with $50 \mu \mathrm{l}$ of a conidial suspension of $1 \times 10^{5}$ conidia $\mathrm{ml}^{-1}$ and incubated in moist chambers for $30 \mathrm{~h}$ at $24^{\circ} \mathrm{C}$. Transverse sections were cut with a razor blade and mounted in water. Micrographs were recorded using an IX-81 Olympus inverted microscope. After 30h, the frequency of M. oryzaerice cell invasion was recorded ( $\mathrm{n}=50$ cells observed, in three replicate experiments). 
1 Evaluation of the effect of chitosan exposure on growth and development of $M$.

2 oryzae

3 Conidia of Guy11 were incubated on hydrophobic glass coverslips in the presence of 0 ,

$40.1,0.5,1,2$ and $5 \mathrm{mg} \mathrm{ml}^{-1}$ chitosan. The frequency of conidial germination was

5 determined after $2 \mathrm{~h}$. The frequency of appressorium development was scored after 4,

$66,8,16$ and $24 \mathrm{~h}$.

7 The effect of chitosan on mycelium growth of M. oryzae was tested as follows. Guy 11,

$8 \Delta$ nox $1, \Delta$ nox $2, \Delta$ nox 1 nox $2, \Delta m p s 1$ and $p k c 1^{A S}$ were grown on CM liquid medium for

$948 \mathrm{~h}$ on an orbital shaker $(150 \mathrm{rpm})$ at $24^{\circ} \mathrm{C}$ with a $12 / 12 \mathrm{~h}$ photoperiod. Mycelium was then transferred to CM medium in the presence/absence of chitosan $\left(0.5\right.$ and $\left.1 \mathrm{mg} \mathrm{ml}^{-1}\right)$ and incubated for a further $48 \mathrm{~h}$. Mycelium was then collected and washed twice with SDW before being lyophilized and the dry weight recorded.

Physiological and cellular response of $M$. oryzae to chitosan during appressorium differentiation

Reporter strains Sep4-GFP::H1-RFP, Sep5-GFP, Gelsolin-GFP, Chm1-GFP, Tea1GFP and Grx1-roGFP2 were used to evaluate the effect of chitosan on cytoskeletal organisation, plasma membrane integrity and cellular oxidative status. A conidial suspension of each strain was incubated in the presence $5 \mathrm{mg} \mathrm{ml}^{-1}$ or absence of chitosan and SDW for $4 \mathrm{~h}, 6 \mathrm{~h}, 8 \mathrm{~h}$ and $24 \mathrm{~h}$ to visualise appressorium development. FM4-64 (N-(3-triethylammoniumpropyl-)-4-(6(4-(diethyl amino) phenyl) hexatrienyl) pyridinium dibromide) was used to evaluate the integrity of the plasma membrane in M. oryzae appressoria exposed to $5 \mathrm{mg} \mathrm{ml}^{-1}$ chitosan. Germlings were observed $24 \mathrm{~h}$ after inoculation. A Grx1-roGFP2 strain (Samalova et al., 2014) was used to detect changes in glutathione oxidation. This had a glutaredoxine (Grx) subunit to improve response kinetics to oxidation in order to evaluate the oxidative response of $M$. oryzae appressoria to either 1 or $5 \mathrm{mg} \mathrm{ml}^{-1}$ chitosan (Samalova et al., 2014). Maximum fluorescence is related to the accumulation of oxidized glutathione a measurement to determine ROS. 
For epifluorescence microscopy, an IX-81 Olympus inverted microscope connected to a CoolSNAP HQ2 camera was used. Three-dimensional projections were captured using a LEICA SP8 LSCM laser confocal scanning microscope, with HyD detectors HC PL APO CS2. Lasers (488nm and 561nm) were used for excitation of GFP and RFP, respectively. Metamorph 7.5 (Molecular Devices) and Image J software (National Institutes of Health, NIH, USA) were used for image analysis. 3D reconstructions were performed with Leica LAS software.

\section{Protoplast release assay}

To evaluate the effect of chitosan on the cell wall composition of $M$. oryzae, we scored the frequency of protoplast release using cell wall degrading enzymes on chitosan grown mycelia. Guy11 was first grown in CM in the presence or absence of 0.5 and 1 $\mathrm{mg} \mathrm{ml}^{-1}$ chitosan for $48 \mathrm{~h}$. Mycelium was then collected using Miracloth and washed twice with SDW, before being transferred to a conical tube with $40 \mathrm{ml}$ of OM buffer (1.2 $\mathrm{M} \mathrm{MgSO}_{4}, 10 \mathrm{mM} \mathrm{NaPO}_{4}$; $\mathrm{pH}$ 5.8) in the presence of $500 \mathrm{mg}$ Glucanex (Sigma) at $\mathrm{pH}$ 5.8. Tubes were then shaken gently to disperse hyphal clumps and then incubated for $3 \mathrm{~h}$ at $30^{\circ} \mathrm{C}$ with gentle $(75 \mathrm{rpm})$ shaking. Isolated protoplasts were transferred to sterile polycarbonate or polysulfonate Oakridge tubes and overlaid with an equal volume of cold ST buffer (0.6 M Sorbitol and 0.1 M Tris-HCl; pH 7.0), before centrifugation at $5,000 \mathrm{~g}$ at $4^{\circ} \mathrm{C}$ for $15 \mathrm{~min}$. Protoplasts were recovered from the OM/ST interface and transferred to a clean Oakridge tube. The tube was filled with STC (1.2 M Sorbitol, $10 \mathrm{mM}$ Tris- $\mathrm{HCl} \mathrm{pH} 7.5$ and $10 \mathrm{mM} \mathrm{CaCl}_{2}$ ). Protoplasts were concentrated by centrifugation at $3,000 \mathrm{rpm} / 10 \mathrm{~min} / 4^{\circ} \mathrm{C}$, in a swinging bucket rotor, before being washed twice more with $10 \mathrm{ml}$ STC. Protoplasts were resuspended in $100 \mu \mathrm{STC}$ buffer and counted.

\section{Quantification of $\beta-1,3$ glucan and chitin in cell walls of $M$. oryzae}

Chitin content of mycelium was estimated by determining the amount of N-acetyl-Dglucosamine according to the method of Bowman et al., (2006) with some modifications as Aranda-Martinez et al., 2016. Guy11 and $\Delta$ noxl strains were first grown in CM for $48 \mathrm{~h}$, mycelium collected, washed twice with SDW and transferred for $48 \mathrm{~h}$ to $\mathrm{CM}$ in the presence or absence of $1 \mathrm{mg} \mathrm{ml}^{-1}$ chitosan. Mycelium was then 
1 collected by centrifugation, washed twice in SDW and lyophilized. Mycelium was

2 ground in liquid nitrogen, and $30 \mathrm{mg}$ per sample hydrolysed in $1 \mathrm{ml} 6 \mathrm{~N} \mathrm{HCl}$ at $110{ }^{\circ} \mathrm{C}$

3 for $6 \mathrm{~h}$. The $\mathrm{HCl}$ was removed by aeration and samples resuspended in $1 \mathrm{ml}$ of SDW

4 before being centrifuged twice at $13,000 \mathrm{rpm}$ for $20 \mathrm{~min}$ in a microfuge. A $0.5 \mathrm{ml}$

5 aliquot of the supernatant from each sample was mixed with $0.1 \mathrm{ml}$ of $0.16 \mathrm{M}$ sodium tetraborate $\mathrm{pH} 9.1$ and then heated at $100^{\circ} \mathrm{C}$ for $3 \mathrm{~min}$. After cooling, $3 \mathrm{ml}$ of $\mathrm{p}$ dimethylamino benzaldehyde (DMAB) solution (10\% DMAB in glacial acetic acid containing $12.5 \% 10 \mathrm{~N} \mathrm{HCl}$, diluted with 9 vol. of glacial acetic acid), was added. The mixture was then incubated for $20 \mathrm{~min}$ at $37^{\circ} \mathrm{C}$ and absorbance at $595 \mathrm{~nm}$ measured in a Genios $^{\mathrm{TM}}$ Multiwell Spectrophotometer (Tecan Group AG). A standard curve was generated using 0-20 $\mathrm{mg} \mathrm{ml}^{-1} \mathrm{~N}$-acetyl-D-glucosamine (Sigma) treated as described previously.

The $\beta$-1,3-glucan content of the fungal cell wall was determined according to Shedletzky et al., (1997) with some modifications (Aranda-Martinez et al., 2016). Mycelium of Guy11 and $\Delta n o x 1$ was transferred to CM in the presence or absence of 1 $\mathrm{mg} \mathrm{ml}^{-1}$ chitosan for $48 \mathrm{~h}$. Mycelium were collected by centrifugation, washed twice in SDW and then hydrolysed with $0.1 \mathrm{M} \mathrm{NaOH}$ before being lyophilized. Mycelium was ground in liquid nitrogen, and $10 \mathrm{mg}$ of grounded mycelium resuspended in $0.5 \mathrm{ml} 1 \mathrm{M}$ $\mathrm{NaOH}$. Samples were incubated at $80^{\circ} \mathrm{C}$ for $30 \mathrm{~min}$ with $0.5 \mathrm{~mm}$ zirconia/silica beads (Biospec) and vortexed several times at full speed for 10 min each to favour tissues disruption. One hundred $\mu$ aliquots from each sample were then mixed with $400 \mu$ of $1 \mathrm{M} \mathrm{NaOH}$. Aniline blue mix $(2.1 \mathrm{ml} ; 40$ vol of $0.1 \%$ aniline blue, 21 vol of $1 \mathrm{~N} \mathrm{HCl}$ and 59 vol of $1 \mathrm{M}$ glycine/ $\mathrm{NaOH}$ buffer; $\mathrm{pH} 9.5$ ) was then added to each sample. These were vortexed and incubated at $50^{\circ} \mathrm{C}$ for $30 \mathrm{~min}$ then incubated for $30 \mathrm{~min}$ at room temperature. Fluorescence was quantified in a Jasco Model FP-6500 spectrofluorometer using $400 \mathrm{~nm}$ excitation and $460 \mathrm{~nm}$ emission wavelengths. A standard curve for $\beta-1,3$-glucan was constructed by using $0-50 \mathrm{mg} \mathrm{ml}^{-1}$ curdlan (Megazyme) dissolved in $0.1 \mathrm{M} \mathrm{NaOH}$ and also heating for $30 \mathrm{~min}$ at $50^{\circ} \mathrm{C}$ in $1 \mathrm{~N}$ $\mathrm{NaOH}$. 
1 Total RNA was obtained from Guy11 and $\Delta$ noxl cultures prepared after $48 \mathrm{~h}$ growth in

$2 \mathrm{CM}$ and further 4,8 and $24 \mathrm{~h}$ growth in the presence or absence of $1 \mathrm{mg} \mathrm{ml}^{-1}$ chitosan.

3 Total RNA was isolated using Trizol reagent (Thermo Fisher Scientific) following 4 manufacturer's instructions. Total RNA was treated with TurboDNA free (Ambion) to 5 remove DNA remains. First strand cDNA was then synthesized using retrotranscriptase RevertAid (Thermo Fisher Scientific) primed with oligo dT (Thermo Fisher Scientific). Gene expression was quantified using real-time reverse transcription PCR (qRT-PCR) with SYBR Green and ROX (Roche). Gene quantification was performed in a Step One Plus real-time PCR system (Applied Biosystems). Relative gene expression was estimated by the $\Delta \Delta \mathrm{Ct}$ methodology (Livak \& Schmittgen, 2001) with three technical replicates per condition. Primers used to quantify the expression of M. oryzae genes in response to chitosan are shown in Table S1. Ubiquitin-conjugate enzyme (MGG_04081) and Glyceraldehyde-3-phosphate dehydrogenase (MGG_01081) genes were used as endogenous controls for all experiments (Che Omar et al., 2016), since their expression showed Ct stability for all conditions tested. We did not use $\beta$-tubulin and actin, commonly used as fungal housekeeping genes, because chitosan modifies their expression (Lopez-Moya et al., 2016). All experiments were repeated three times.

\section{Results}

\section{Exposure to chitosan reduces the ability of $M$. oryzae to cause rice blast disease}

In order to determine the effect of chitosan on the growth and development of the rice blast fungus $M$. oryzae, conidia were exposed to chitosan and then used to inoculate the susceptible rice cultivar CO-39. In leaf drop experiments, $M$. oryzae normally displays a large necrotic, sporulating disease lesion, as shown in Fig. 1a. However, when leaves were inoculated with $M$. oryzae in the presence of chitosan, mildly necrotic, nonsporulating lesions resulted (Fig. 1a). When conidial suspensions were used to sprayinoculate rice seedlings, exposure to chitosan $\left(5 \mathrm{mg} \mathrm{ml}^{-1}\right)$ significantly $(\mathrm{p}<0.05)$ reduces the generation of rice blast disease lesions (Figs. 1b,c). However, spraying chitosan only in a mock inoculation does not cause any damage or response on rice leaves (Fig. 1b). Microscopic examination of rice leaf sheath preparations inoculated 
1 with $M$. oryzae conidia exposed to chitosan $\left(5 \mathrm{mg} \mathrm{ml}^{-1}\right)$ showed a $75 \%$ reduction in the number of cells penetrated by the fungus, compared to non-exposed, as shown in Fig. 1d. Differentiated appressoria from chitosan-treated conidia either did not penetrate epidermal rice leaf cells, or displayed a reduced invasive growth and colonisation of adjacent epidermal cells, as shown in Figs. 1e,f.

6 Exposure to chitosan impairs appressorium development and function in $M$. oryzae

8 Chitosan exposure reduces the frequency of appressorium differentiation when applied to un-germinated $M$. oryzae conidia in a concentration-dependent manner, as shown in Fig. 2. Chitosan exposure did not affect the rate of conidial germination (Fig. S1), but after $4 \mathrm{~h}$ exposure to chitosan $\left(0.5-2 \mathrm{mg} \mathrm{ml}^{-1}\right)$ the number of differentiated appressoria was significantly reduced $(\mathrm{p}<0.05)$. Exposure to a concentration of $5 \mathrm{mg} \mathrm{ml}^{-1}$ chitosan was sufficient to almost completely prevent appressorium differentiation (Figs. 2a,b). After $6 \mathrm{~h}$ exposure to $5 \mathrm{mg} \mathrm{ml}^{-1}$ chitosan appressorium development was decreased by $85 \%$. Exposure to low or intermediate concentrations of chitosan (between $0.5-2 \mathrm{mg}$ $\mathrm{ml}^{-1}$ ) still cause a significant inhibition of appressorium development. Exposure to high doses of chitosan $\left(5 \mathrm{mg} \mathrm{ml}^{-1}\right)$ also caused an effect on appressorium shape, reducing the size of incipient appressoria (Fig. 2c and Fig. S2) and preventing formation of the appressorium melanin layer (Fig. 2d), which is essential for M. oryzae pathogenicity (Howard \& Ferrari, 1989; Howard et al., 1991).

Exposure to chitosan prevents septin recruitment and organisation of the appressorium pore

Appressorium re-polarisation requires recruitment and organisation of a heterooligomeric ring of septin GTPases at the appressorium pore (Dagdas et al., 2012). In order to determine the effect of chitosan exposure on septin-dependent plant infection chitosan was applied to un-germinated conidia and the localisation of Sep4-GFP was investigated by live cell imaging, as shown in Fig. 3. M. oryzae appressoria normally form a large septin ring, of approximately $5.9 \mu \mathrm{m}$ in diameter (Dagdas et al., 2012), as shown in Fig. 3a. Exposure to $5 \mathrm{mg} \mathrm{ml}^{-1}$ chitosan for $8 \mathrm{~h}$ led to septin accumulation, as dense body in the centre of incipient appressoria, but no organisation into a ring 
1 structure (Fig. 3a). Similarly, when the actin-binding protein gelsolin was visualised by expression of Gelsolin-GFP, this normally formed a ring structure at the appressorium pore, which did not form following exposure of M. oryzae to chitosan (Fig. 3b). Consistent with the observed effect of chitosan exposure on septin organisation at the appressorium pore, the localisation of Chm1-GFP, which encodes the plasma membrane kinase which phosphorylates septins, was also affected by exposure to chitosan (Fig. 3c). Polarity determinants, such as Tea1, an F-actin-plasma membrane protein with a $\mathrm{C}$-terminal actin-binding domain and $\mathrm{N}$-terminal ERM domain (Gilden \& Krummel, 2010) are also disorganized by exposure to chitosan (Fig. 3d). When appressoria were visualised at $24 \mathrm{~h}$, chitosan exposure was still sufficient to impair septin and F-actin ring organisation in M. oryzae appressoria (Figs. S3, S4 and S5). Quantitative analysis confirmed that chitosan treatment reduced the frequency of development of intact septin rings and the organisation of each component visualised (Fig. 3e,f,g,h).

In order to establish the stage at which septin organisation was perturbed by chitosan exposure, we decided to apply chitosan to $M$. oryzae germlings in a time-course experiments at $4 \mathrm{~h}, 8 \mathrm{~h}, 14 \mathrm{~h}$ and $16 \mathrm{~h}$ after conidial germination. We found that chitosan exposure at early stages of appressorium development, between $4-8 \mathrm{~h}$ after conidial germination, prevented septin ring organisation (Fig S6; Supplementary Movie 1). There is clearly a window of activity at which chitosan exerts its effect, prior to $8 \mathrm{~h}$. After this point, the septin ring has already formed and chitosan exposure has no effect on its organisation (Fig. S6). We conclude that exposure to chitosan prevents septindependent cytoskeletal changes necessary for plant infection by the rice blast fungus.

\section{Chitosan permeabilises plasma membrane and perturbs the regulated synthesis of reactive oxygen species during appressorium development}

The main cellular change previously reported to occur following chitosan exposure is plasma membrane permeabilization (Palma-Guerrero et al., 2009; Palma-Guerrero et al., 2010). To determine if this occurs upon exposure of $M$. oryzae to chitosan, the lipophilic styryl dye, FM4-64 was applied to germinating conidia in the presence or absence of chitosan (Fig. 4a). Large-scale plasma membrane permeabilization was 
1 evident based on widespread FM4-64 fluorescence detected in appressoria in the

2 chitosan treated samples, 10min after chitosan treatment (Fig. 4b).

3 The regulated synthesis of reactive oxygen species (ROS) is essential for appressorium

4 development and necessary for septin organisation and penetration peg formation

5 (Ryder et al., 2013). On the contrary, plasma membrane permeabilization by chitosan

6 exposure leads to massive ROS generation and cell death (Lopez-Moya et al., 2015).

7 We therefore decide to use strain of M. oryzae, expressing Grx1-roGFP2 which detects

8 changes in glutathione oxidation to measure ROS accumulation in $M$. oryzae

9 appressoria. We observed a significant $(\mathrm{p}<0.05)$ reduction in Grx1-roGFP2

10 fluorescence in appressoria following exposure to $5 \mathrm{mg} \mathrm{ml}^{-1}$ chitosan for $8 \mathrm{~h}$ (Fig. $4 \mathrm{c}$ and 4d). We also observed in Guy11 elevated expression of the NOX2 NADPH oxidase, but a small decrease in NOX1 expression in response to chitosan treatment (Fig. 4e). To investigate this response further, we then examined the expression of NOX2 in a $\triangle$ noxl mutant. We observed increased NOX2 expression in the $\Delta$ noxl mutant in the presence of chitosan (Fig. S7). We conclude that chitosan exposure increases ROS generation and permeabilizes plasma membrane of the rice blast fungus.

\section{Sensitivity to chitosan requires Nox1-dependent NADPH oxidase activity}

Given the effect of chitosan exposure to ROS generation and membrane permeability in M. oryzae, we decided to investigate the phenotype of chitosan treatment on $\Delta$ noxl, $\Delta$ nox 2 mutants, lacking the respective catalytic sub-units of the NADPH oxidases (Egan et al., 2007). To carry out this experiment, we exposed each mutant to 0.5-1 mg $\mathrm{ml}^{-1}$ chitosan and measured their vegetative growth in liquid CM cultures, based on dry weight. Then, we observed that chitosan exposure-initiated accumulation of melanin in culture filtrates of the wild-type strain Guy 11 and in the $\Delta$ nox2 mutant, albeit only in response to higher chitosan concentrations (Fig. 5a). Strikingly, however, Anoxl mutants did not secrete excess melanin (Fig. 5a). Consistent with the difference in appearance of liquid cultures, we found that $\Delta$ noxl mutants were more resistant to chitosan exposure, than Guy11 and $\Delta$ nox2 mutants, which both showed significant reductions in dry weight following exposure to chitosan compared to the $\Delta$ noxl mutant (Fig. 5b). We observed that chitosan treatment of a $\Delta$ noxlnox2 double mutant did not 
cause any reduction in biomass and cultures continued to grow very well (Fig. 5b). This suggests that absence of the Nox1 catalytic sub-unit of the NADPH oxidase complex leads to enhanced tolerance to chitosan treatment and that this remains unaffected by further loss of Nox2.

\section{Sensitivity to chitosan requires the protein kinase C-dependent cell wall integrity pathway in M. oryzae}

The $\Delta$ noxl mutant has previously been shown to be more resistant to calcofluor white (Egan et al., 2007), suggesting that Nox1 is critical for correct cell wall biosynthesis. This is consistent with its role in penetration peg elongation and invasive fungal growth (Ryder et al., 2013). We reasoned that the resistance to chitosan treatment shown by $\Delta$ noxl mutants may suggest that the uptake and/or fungicidal role of chitosan may be dependent on correct organisation of the fungal cell wall. To test this idea, we evaluate the effect of chitosan on $\Delta m p s 1$ mutants, impaired in function of the cell wall integrity pathway (Xu et al., 1998). The Mps1 MAP kinase is important for hyphal growth, conidiation and appressorium function and mutants show defects in their regulation of cell wall biogenesis ( $\mathrm{Xu}$ et al., 1998). We observed that $\Delta m p s 1$ mutants showed enhanced resistance to chitosan exposure, growing as well as a $\Delta$ noxlnox2 double mutant in the presence of high concentrations of chitosan (Fig. 5b).

The cell wall integrity pathway is regulated by protein kinase C (Levin 2011) and in $M$. oryzae, $P K C 1$ is an essential gene required for cell viability (Penn et al., 2015). To test whether chitosan sensitivity requires Pkc1-dependent signalling, we therefore used an analogue-sensitive mutant of Pkc1, which is sensitive to the ATP analogue 4-amino-1tert-butyl-3-(1'-naphthyl) pyrazolo[3,4-d] pyrimidine (NA-PP1). This was generated by mutation of the gatekeeper residue of the ATP-binding pocket of Pkc1 and targeted allelic replacement to provide a mutant in which Pkc1 activity can be specifically inhibited by application of 1NA-PP1 (described by Penn et al., 2015). This mutant normally fails to grow in the presence of 1NA-PP1. We incubated the $p k c 1^{A S}$ mutant in the presence or absence of chitosan and $1 \mu \mathrm{M}$ NA-PP1. The lethal effect of 1NA-PP1 was partially remediated by the presence of chitosan, allowing some fungal growth to occur, as shown in Fig. 5c. This result is consistent with absence of the Pkc1-dependent 
1 protein kinase $\mathrm{C}$ pathway leading to enhanced resistance to chitosan. However, the

2 partial remediation of the lethal effect of losing Pkc1 activity by chitosan may also

3 point to a more direct role for chitosan in stabilising the cell wall when it is affected in

4 composition by impairment of the cell wall integrity signalling pathway.

5 To investigate the effect of chitosan on cell wall composition in M. oryzae, we carried 6 out a protoplast release assay, which evaluates the sensitivity of the cell wall to cell 7 wall degrading enzymes. We treated fungal mycelium grown in the presence or absence of chitosan (0.5 and $1 \mathrm{mg} \mathrm{ml}^{-1}$ ), with Glucanex (Sigma Aldrich), a commercial preparation of glucanases and chitinases, to release protoplasts. We observed that mycelium grown in the presence of chitosan was more resistant to cell wall degrading enzymes, showing significantly $(\mathrm{p}<0.0001)$ less protoplast release (Fig. 5d and Fig. S8).

We then determined the chitin and glucan content of cells walls of mycelium of $M$. oryzae, grown in the presence or absence of chitosan (Fig. 5e,f). We observed that chitosan exposure led to a significant decrease in chitin content and increase in glucan content of fungal cell walls of the wild-type strain Guy11. Interestingly, when we repeated this assay in a $\Delta$ noxl mutant, we observed an elevated chitin content and reduced glucan content in the mutant, when grown normally in the absence of chitosan. Chitosan treatment led to a decrease in chitin content of a $\Delta$ noxl mutant, but these levels were still the same as in those in Guy11 grown normally. Furthermore, there was little overall effect on glucan content in the $\Delta$ noxl mutant when exposed to chitosan (Fig. 5e,f). These observations suggest that the $\Delta$ noxl mutant may be resistant to chitosan due to its enhanced glucan/chitin cell wall ratio. Consistent with the importance of Nox 1 function in the response to chitosan, live cell imaging experiments of a $M$. oryzae strain expressing Nox1-GFP revealed misslocalisation of the NADPH oxidase after exposure to chitosan. Nox1-GFP is normally located at the appressorium cortex in $24 \mathrm{~h}$ appressoria. However, in appressoria developed in the presence of a high chitosan dose $\left(5 \mathrm{mg} \mathrm{ml}^{-1}\right)$, Nox1-GFP was located in the central appressorium vacuole (Fig. 5g). When considered together, our observations suggest that the cell wall integrity pathway is critical to the fungicidal activity of chitosan and this may be linked to the glucan/chitin ratio of fungal cell walls. 
1 Exposure to chitosan causes repression of cell wall integrity pathway gene

2

3 expression

To characterise the link between the cell wall integrity pathway and the response of $M$. oryzae to chitosan, we studied expression of genes encoding components of the cell wall integrity pathway in mycelium grown in the presence or absence of chitosan. We observed that chitosan exposure led to repression in the expression of MPS1, PKC1, RHOI and SWI6 in Guy 11 (Fig. 6). In all cases the effect was most pronounced after $8 \mathrm{~h}$ exposure, but some repression was maintained even after $24 \mathrm{~h}$ exposure to chitosan. When the same genes were analysed in a $\Delta$ noxl mutant in the presence or absence of chitosan, we observed that chitosan exposure led to elevated expression of $P K C 1$, MPS1, RHO1 and SWI6 after 24h exposure (Fig. 6). MPS1 expression was initially reduced in the $\Delta$ noxl mutant when exposed to chitosan for $8 \mathrm{~h}$, but then showed elevated expression by $24 \mathrm{~h}$. The overall pattern of gene expression suggests that chitosan treatment normally leads to repression of the cell wall integrity pathway. By contrast, the absence of the Nox1 NADPH oxidase prevents this repression mediated by chitosan exposure and instead leads to elevated expression. Taken together, these results are consistent with cell wall integrity pathway function being essential for the fungicidal activity of chitosan.

\section{Discussion}

Chitosan has considerable potential as a naturally occurring anti-fungal agent. It can be readily produced by partial deacetylation of chitin, one of the most common biopolymers, a constituent of the cell walls of fungi, and the exoskeletons of arthropods and crustaceans (Allan \& Hadwiger, 1979). Commercially, chitosan can be produced in large quantities, for example, from crab shell waste (Kumar, 2000). In addition to being a highly toxic cationic inhibitor of the growth of many fungal species, including important plant pathogens, chitosan is not toxic to mammals, including humans (Lopez-Moya et al., 2015), or to plants leaves, where it can act instead as a plantdefence inducing compound (Trotel-Aziz et al., 2006). Chitosan therefore has considerable potential to treat plant diseases, but its mode-of-action is still not completely clear. 
In this study we set out to determine the effects of chitosan treatment on the rice blast fungus $M$. oryzae, one of the world's most devastating crop pathogens, which causes very substantial losses to the annual rice harvest (Wilson \& Talbot, 2009; Martin-Urdiroz et al., 2016). The infection mechanism of M. oryzae has also been intensively studied making it an excellent model for understanding how chitosan might act in the context of perturbing plant infection by a phytopathogenic fungus.

First of all, we have demonstrated that chitosan is able to inhibit the growth of M. oryzae and its ability to cause rice blast disease. It is known that chitosan forms part of the differentiated cell wall of $M$. oryzae during appressorium-mediated plant infection (Geoghegan \& Gurr, 2016), but the fungicidal action of exogenously applied chitosan to M. oryzae has not previously been shown. We observed that chitosan blocks appressorium-mediated plant infection by the fungus and is able to prevent organisation of the septin ring, that is necessary for F-actin re-organisation at the appressorium pore. Four core septins, Sep3, Sep4, Sep5 and Sep6 are essential for generating a heterooligomeric ring structure that bounds the appressorium pore and is essential for plant infection (Dagdas et al., 2012). Formation of this ring structure is pivotal to penetration peg development and therefore rupture of the rice cuticle. The septin ring acts as a scaffold to organise F-actin at the point of infection and as a lateral diffusion barrier to hold polarity determinants, such as Tea1, Cdc42, and Las17 at the centre of the pore, from where formation of the penetration peg occurs (Dagdas et al., 2012; Ryder et al., 2013). Chitosan prevents these developmental changes from occurring and polarity of the appressorium is thus impeded, preventing plant infection. Septins are well known regulators of polarity and fungal morphogenesis in filamentous fungi, such as Aspergillus nidulans and Neurospora crassa (Berepiki \& Read, 2013) and yeasts such as S. cerevisiae and Schizosaccharomyces pombe (Gladfelter et al., 2005; HernandezRodriguez \& Momany, 2012). Consistent with this effect on septin recruitment and organisation, previous transcriptional profiling experiments in $N$. crassa show that chitosan exposure represses expression of the core septin-encoding genes CDC10, CDC11, and CDC12 (Lopez-Moya et al., 2016). The inhibition of septin recruitment was also shown to impair F-actin organisation during appressorium differentiation and the localisation of Tea1 and Chm1. This is consistent with chitosan preventing 
appressorium function due to an inability to carry out the rapid septin-dependent, actin polymerisation at the base of the infection cell, necessary for re-polarisation. In $N$. crassa, proteins associated with actin polymerisation proteins are also repressed by chitosan (Lopez-Moya et al., 2016). These results support the hypothesis that one of the consequences of chitosan exposure is to disrupt cytoskeletal organisation.

To investigate the primary mode-of-action of chitosan we decided to evaluate its effect on the plasma membrane and cell wall. Previous studies have shown that chitosan exposure causes plasma membrane permeabilisation (Palma-Guerrero, et al., 2009; Jaime et al., 2012, Lopez-Moya, et al., 2015). It is known that chitosan permeabilises plasma membrane in an ATP-dependent manner in N. crassa (PalmaGuerrero, et al., 2009) and that its toxicity is dependent on membrane fluidity. A fatty acid desaturase mutant, $\Delta o d s$, showing reduced plasma membrane fluidity exhibited increased resistance to chitosan (Palma-Guerrero et al., 2010). Chitosan resistant fungi, such as the nematophagous fungus Pochonia chlamydosporia, also showed reduced polyunsaturated fatty acid content in the plasma membranes (Palma-Guerrero et al., 2010). We observed that chitosan exposure led to plasma membrane permeabilization in $M$. oryzae, consistent with these previous studies. Permeabilization and disruption of membrane integrity may lead to the changes in septin organisation observed, given the importance of the plasma membrane cytoskeleton scaffolding (Porter \& Day, 2015).

It is known that membrane-localised NADPH oxidases are key to regulating the recruitment and organisation of septins during plant infection by $M$. oryzae (Egan et al., 2007 and Ryder et al., 2013). We observed that chitosan exposure causes massive ROS synthesis, consistent with its effects on septin recruitment. In this sense, we also observed elevated expression of NOX2 by chitosan treatment. We also found that a $\Delta$ noxl mutant, which lacks one of the catalytic sub-units of NADPH oxidase, is more resistant to chitosan treatment. Previously it has been reported that Nox1 is required for cell wall organisation in $M$. oryzae as $\Delta$ noxl mutants show greater resistance to calcofluor white (Egan et al., 2007). It is also known that Nox1 is necessary for penetration peg elongation and is therefore likely to be a key regulator of cell wall biosynthesis. We observed that $\Delta$ noxl mutants showed a higher chitin content than an 
isogenic wild-type strain of M. oryzae and this may have contributed to its resistance to chitosan, as exposure to chitosan appears to deplete the fungus of chitin in its cell walls. The imbalance in chitin and glucan content caused by chitosan exposure may be an important element of its toxicity and may also be associated with the ability of chitosan to traverse the wall effectively in order to bind to its primary target, the plasma membrane (Palma-Guerrero et al., 2009; Palma-Guerrero et al., 2010; LopezMoya et al., 2015; Lopez-Moya et al., 2016; Aranda-Martinez et al., 2016).

The importance of the fungal cell wall in conditioning the response of M. oryzae to chitosan exposure led us to examine mutants in key components of the cell wall integrity pathway. The cell wall integrity pathway is well known to mediate the response to cell wall stress and is therefore associated with osmotic stress adaptation and xenobiotic stresses, including drug treatments (Bahn et al., 2007; LaFayette et al., 2010; Penn et al., 2015). We found that chitosan exerts its toxicity towards M. oryzae through a process dependent on a functional cell wall integrity pathway. A $\Delta m p s 1$ mutant lacking the cell wall integrity MAP kinase, was more tolerant to chitosan than the wild-type strain. MPS1, PKC1, SWI6 and RHOI genes were all repressed in response to chitosan treatment. $\mathrm{RHOI}$ controls cell wall synthesis and aggregation of actin cables in M. oryzae (Fu et al., 2018) and its down-regulation in response to chitosan is consistent with the defects in F-actin organisation observed after drug treatment. Protein kinase $\mathrm{C}$, which acts as a major control point for operation of the cell wall integrity pathway is essential in $M$. oryzae, but we found that a conditionally lethal, analogue-sensitive mutant of PKCl (Penn et al., 2015), could be partially remediated for growth in the presence of chitosan. This result strongly suggests that chitosan can partially serve to stabilise cell wall integrity in the absence of the PKC signalling pathway in a way that allows some fungal growth to occur. It is clear, however, that when the PKC cell wall integrity pathway is fully operational, chitosan can permeabilise the cell membrane, affect NADPH oxidase functions, disorganize septin and disrupting the actin cytoskeleton. The role of the Nox1 NADPH oxidase in regulating cell wall biogenesis is also clear, because its absence renders the fungus much less sensitive to chitosan, up-regulates genes encoding components of the PKC cell wall integrity pathway in the presence of chitosan, and leads to an elevated chitin 
1 cell wall content. This change in cell wall composition explains the previously reported resistance of $\Delta$ noxl mutants to calcofluor white (Egan et al., 2007) and reveals the importance of cell wall function to the ability of chitosan to inhibit fungal growth.

Chitosan is therefore a potential means by which rice blast disease could be controlled in future, given its ability to prevent leaf infection at a very early stage, prior to cuticle penetration. Furthermore, because chitosan is likely to act at multiple sites in conditioning membrane permeabilization, the chances of selecting specific resistant mutants is likely to be very low. Results here also show how increased tolerance to chitosan, which might emerge by perturbation of cell wall function is unlikely to result in mutants that could survive under field conditions because of the essential nature of cell wall composition and its regulation to growth and development. In conclusion, we show new data on the mode of action of chitosan useful to control a plant pathogen threatening global food security. We propose chitosan as a useful tool to modify fungal morphogenesis, gene expression and pathogenicity. Our results are, therefore, of paramount importance for developing chitosan as a natural antifungal to control rice blast.

\section{Acknowledgements}

This work was supported by AGL 2015 66833-R grant from the Spanish Ministry of Economy and Competitiveness and European H2020 Project MUSA-727624. We would like to thank Dr Nuria Escudero (Microomics Systems S.L.) and Msc Neftaly Cruz-Meireles (TSL) for their technical support. Authors would like to thank Dr Mick Kershaw (University of Exeter) for his contribution for manuscript editing.

\section{Author Contribution}

F. L-M: design and performance of the research, data collection and data analysis, writing the manuscript., M. M-U.: performance of the research and technical support and data interpretation, M. O-R.: performance of the research and technical support and data interpretation, M. F.: ro-GFP results analysis and other data interpretation, G.L.: performance of the research and technical support with confocal imaging and data interpretation, L.V. L-L1.: design of the research, performance of the research, data 
1 interpretation, writing the manuscript. , N.J.T.: design of the research, data

2 interpretation, writing the manuscript.

3

Al-Hetar MY, Zainal AMA, Sariah M, Wong MY. 2010. Antifungal activity of chitosan against Fusarium oxysporum f. sp. cubense. Journal of Applied Polymer Science. 120(4): 2434-2439.

Allan CR, Hadwiger LA. 1979. The fungicidal effect of chitosan on fungi of varying cell wall composition. Experimental Mycology. 3 (3): 285-287.

Aranda-Martinez A, Lopez-Moya L, Lopez-Llorca LV. 2016. Cell wall composition plays a key role on sensitivity of filamentous fungi to chitosan. Journal of Basic Microbiology. 56(10):1059-1070.

Bah, Y-S., Xue, C., Idnurm, A., Rutherford, JC, Heitman J., Cardenas, ME. 2007. Sensing the environment: lessons from fungi. Nature Reviews Microbiology. 5: 57-69.

Barja F, Chappuis M-L, Turian G. 1993. Differential effects of anticytoskeletal compounds on the localization and chemical patterns of actin in germinating conidia of Neurospora crassa. FEMS Microbiology Letters. 107: 261-266.

Berepiki A, Read ND. 2013. Septins are important for cell polarity, septation and asexual spore formation in Neurospora crassa and show different patterns of localisation at germ tube tips. PLoS One. 8(5): e63843.

Berepiki A, Lichius A, Shoji JY, Tilsner J, Read ND. 2010. F-actin dynamics in Neurospora crassa. Eukaryotic Cell. 9(4): 547-57.

Bowman SM, Piwowar A, Dabbous MA, Vierula J, Free SJ. 2006. Mutational analysis of the glycosylphosphatidylinositol (GPI) anchor pathway demonstrates that GPI-anchored proteins are required for cell wall biogenesis and normal hyphal growth in Neurospora crassa. Eukaryotic Cell. 5, 587-600. 
1 Castroagudin VL, Ceresini PC, de Oliveira SC, Reges JT, Maciel JL, Bonato AL, Dorigan AF, McDonald BA. 2015. Resistance to QoI Fungicides Is Widespread in Brazilian Populations of the Wheat Blast Pathogen Magnaporthe oryzae. Phytopathology. 105(3): 284-94.

Che Omar S, Bentley MA, Morieri G, Preston GM, Gurr SJ. 2016. Validation of Reference Genes for Robust qRT-PCR Gene Expression Analysis in the Rice Blast Fungus Magnaporthe oryzae. PLoS One. 11(8): e0160637.

Chumley FG, Valent B. 1990. Genetic analysis of melanin-deficient nonpathogenic mutants of Magnaporthe grisea. Molecular Plant Microbe Interactions. 3(3): 135-143.

Dagdas YF, Yoshino K, Dagdas G, Ryder LS, Bielska E, Steinberg G, Talbot NJ. 2012. Septin-mediated plant cell invasion by the rice blast fungus, Magnaporthe oryzae. Science. 336(6088): 1590-5.

de Jong J, McCormack B, Smirnoff N, Talbot NJ. 1997. Glycerol generates turgor in rice blast. Nature. 389, 244.

Dirschnabel DE, Nowrousian M, Cano-Domínguez N, Aguirre J, Teichert I, Kück U. 2014. New insights into the roles of NADPH oxidases in sexual development and ascospore germination in Sordaria macrospora. Genetics. 196(3): 729-44.

Eaton CJ, Cox MP, Scott B. 2011. What triggers grass endophytes to switch from mutualism to pathogenism? Plant Science. 180(2):190-5.

Egan MJ, Wang ZY, Jones MA, Smirnoff N, Talbot NJ 2007. Generation of reactive oxygen species by fungal NADPH oxidases is required for rice blast disease. Proceedings of the National Academy of Sciences of the United States of America. 104 (28): 11772-7.

Fisher, MC, Henk, DA, Briggs, CJ, Brownstein, JS, Madoff, LC, McCraw, SL, Gurr, SJ. 2012. Emerging fungal threats to animal, plant and ecosystem health. Nature. 484: 186-194. 
1 Fisher, MC, Hawkins, NJ, Sanglard, D, Gurr, SJ. 2018 Worldwide emergence of resistance to antifungal drugs challenges human health and food security. Science. 360: $739-742$

Fu T, Kim JO, Han JH, Gumilang A, Lee YH, Kim KS. 2018. A Small GTPase RHO2 plays an important role in pre-infection development in the rice blast pathogen Magnaporthe oryzae. Plant Pathology Journal. 34(6):470-479.

Geoghegan IA, Gurr SJ. 2016. Chitosan mediates germling adhesion in Magnaporthe oryzae and is required for surface sensing and germling morphogenesis. PLoS Pathogens. 12(6): e1005703.

Gilden J, Krummel MF. 2010. Control of cortical rigidity by the cytoskeleton: emerging roles for septins. Cytoskeleton (Hoboken). 67(8): 477-86.

Gladfelter AS, Kozubowski L, Zyla TR, Lew DJ. 2005. Interplay between septin organization, cell cycle and cell shape in yeast. Journal of Cell Science. $118(\mathrm{Pt}$ 8): 1617-28.

Hernandez-Rodriguez Y, Momany M. 2012. Posttranslational modifications and assembly of septin heteropolymers and higher order structures. Current Opinion in Microbiology. 15: 660-668.

Howard RJ, Ferrari MA. 1989. Role of melanin in appressorium function. Experimental Mycology. 13: 403-418.

Howard RJ, Ferrari MA, Roach DH, Money NP. 1991. Penetration of hard substrates by a fungus employing enormous turgor pressures. Proceedings of the National Academy of Sciences of the United States of America. 88(24): 1128111284.

Howard RJ, Valent B. 1996. Breaking and entering: host penetration by the fungal rice blast pathogen Magnaporthe grisea. Annual Review of Microbiology. 50:491-512. 
Jaime MDLA, Lopez-Llorca LV, Conesa A, Lee AY, Proctor M, Heisler LE, Gebbia M, Giaever G, Westwood JT, Nislow C. 2012. Identification of yeast genes that confer resistance to chitosan oligosaccharide (COS) using chemogenomics. BMC Genomics. 13(1): 267.

Kumar RMNV. 2000. A review of chitin and chitosan applications. Reactive and Functional Polymers. 46(1): 1-27.

LaFayette SL, Collins C, Zaas AK, Schell WA, Betancourt-Quiroz M, Gunatilaka AAL, Perfect JR, Cowen LE. 2010. PKC signalling regulates drug resistance of the fungal pathogen Candida albicans via circuitry comprised of Mkc1, calcineurin and Hsp90. PLoS Pathogens 6: e1001069.

Leung, H, Borromeo, ES, Bernardo, MA, Notteghem, JL. 1988. Genetic analysis of virulence in the rice blast fungus Magnaporthe grisea. Phytopathology. 78:1227-1233.

Levin D. E. 2011. Regulation of cell wall biogenesis in Saccharomyces cerevisiae: the cell wall integrity signalling pathway. Genetics. 189(4), 1145-1175.

Li L, Xue C, Bruno K, Nishimura M, Xu JR. 2004. Two PAK kinase genes, CHM1 and MST20, have distinct functions in Magnaporthe grisea. Molecular Plant Microbe Interactions. 17(5): 547-56.

Livak and Schmittgen. 2001. Analysis of relative gene expression data using real-time quantitative PCR and the 2(-Delta Delta C(T)) Method. Methods. 25(4):402-8.

Lopez-Moya F, Colom-Valiente MF, Martinez-Peinado P, Martinez-Lopez JE, Puelles E, Sempere-Ortells JM, Lopez-Llorca LV. 2015. Carbon and nitrogen limitation increase chitosan antifungal activity in Neurospora crassa and fungal human pathogens. Fungal Biology. 119(2-3): 154-169.

\section{Lopez-Moya F, Kowbel D, Nueda MJ, Palma-Guerrero J, Glass NL, Lopez-Llorca} LV. 2016. Neurospora crassa transcriptomics reveals oxidative stress and plasma membrane homeostasis biology genes as key targets in response to chitosan. Molecular Biosystems. 12(2): 391-403. 
Lucas, JA, Hawkins NJ, Fraaije, BA. 2015. The evolution of fungicide resistance. Advances in Applied Microbiology. 90: 29-92.

Martin-Urdiroz M, Oses-Ruiz M, Ryder LS, Talbot NJ. 2016. Investigating the biology of plant infection by the rice blast fungus Magnaporthe oryzae. Fungal Genetics and Biology. 90: 61-8.

Muñoz Z, Moret A. 2010. Sensitivity of Botrytis cinerea to chitosan and acibenzolarS-methyl. Pest Management Science. 66(9):974-9.

Palma-Guerrero J, Jansson HB, Salinas J, Lopez-Llorca LV. 2008. Effect of chitosan on hyphal growth and spore germination of plant pathogenic and biocontrol fungi. Journal of Applied Microbiology. 104(2): 541-53.

\section{Palma-Guerrero J, Huang I, Jansson HB, Salinas J, Lopez-Llorca LV, Read ND.} 2009. Chitosan permeabilizes the plasma membrane and kills cells of Neurospora crassa in an energy dependent manner. Fungal Genetics and Biology. 46(8): 585-594.

Palma-Guerrero J, Lopez-Jimenez J, Pérez-Berná AJ, Huang IC, Jansson HB, Salinas J, Villalaín J, Read ND, Lopez-Llorca LV. 2010. Membrane fluidity determines sensitivity of filamentous fungi to chitosan. Molecular Microbiology. 75(4): 1021-1032.

Penn, TJ, Wood, ME, Soanes, DM, Csukai, M, corran, AJ, Talbot, NJ. 2015. Protein kinase $\mathrm{C}$ is essential for viability of the rice blast fungus Magnaporthe oryzae. Molecular Microbiology. 98:403-19.

Porter K, Day B. 2015. From filaments to function: The role of the plant actin cytoskeleton in pathogen perception, signalling and immunity. Journal of Integrative Plant Biology. 58(4): 299-311.

\section{Ryder LS, Dagdas YF, Mentlak TA, Kershaw MJ, Thornton CR, Schuster} M, Chen J, Wang Z, Talbot NJ. 2013. NADPH oxidases regulate septinmediated cytoskeletal remodelling during plant infection by the rice blast 
fungus. Proceedings of the National Academy of Sciences of the United States of America. 110(8): 3179-84.

Ryder LS, Dagdas YF, Kershaw MJ, Venkataraman C, Madzvamuse A, Yan X, Cruz-Mireles N, Soanes DM, Oses-Ruiz M, Styles V, Sklenar J, Menke FLH, Talbot NJ. 2019. A sensor kinase controls turgor-driven plant infection by the rice blast fungus. Nature. 574(7778):423-427.

Samalova M, Meyer AJ, Gurr SJ, Fricker MD. 2014. Robust anti-oxidant defences in the rice blast fungus Magnaporthe oryzae confer tolerance to the host oxidative burst. New Phytologist. 201(2): 556-73.

Shedletzky E, Unger C, Delmer DP. 1997. A microtiter-based fluorescence assay for $(1,3)$ - $\beta$-glucan synthases. Analytical Biochemistry. 249, 88-93.

Talbot NJ, Ebbole DJ, Hamer JE. 1993. Identification and characterization of MPG1, a gene involved in pathogenicity from the rice blast fungus Magnaporthe grisea. Plant Cell. 5(11): 1575-1590.

Talbot NJ. 2003. On the trial of a cereal killer: Exploring the biology of Magnaporthe grisea. Annual Review of Microbiology. 57: 177-202.

Trotel-Aziz P, Couderchet M, Vernet G, Aziz A. 2006. Chitosan stimulates defense reactions in grapevine leaves and inhibits development of Botrytis cinerea. European Journal of Plant Pathology. 114: 405-413.

Wilson RA, Talbot NJ. 2009. Under pressure: investigating the biology of plant infection by Magnaporthe oryzae. Nature Review of Microbiology. 7:185-195.

Xu, JR, Staiger CJ., Hamer, JE. 1998. Inactivation of the mitogen-activated protein kinase Mps1 from the rice blast fungus prevents penetration of host cells but allows activation of plant defense responses. Proceedings of the National Academy of Sciences of the United States of America. 95: 12713.

Wei W., Wenjun Z., Cheng J, Xie J, Jiang D, Li G., Chen W., Fu Y. 2016. Nox Complex signal and MAPK cascade pathway are cross-linked and essential for 
pathogenicity and conidiation of mycoparasite Coniothyrium minitans. Scientific Reports. 6: 24325.

Zhang C, Xin H, Jian-Xin W, Ming-Guo Z. 2009. Resistance development in rice blast disease caused by Magnaporthe grisea to tricyclazole. Pesticide Biochemistry and Physiology. 4(1): 43-47.

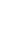

(1)

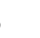

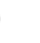

\section{Figure Caption}

Figure 1. Chitosan reduces pathogenicity of $M$. oryzae on rice plants. a) Chitosan reduces pathogenicity of $M$. oryzae on leaf cuticle in a leaf spot bioassay after $5 \mathrm{~d}$. b) Chitosan reduces the number of lesions caused by $M$. oryzae on rice leaves in leaf spray bioassays after $5 \mathrm{~d}$. c) Chitosan significantly reduces the number of lesions per leaf after $M$. oryzae spray and incubation for $5 \mathrm{~d}$. Asterisk indicates significant differences. Multifactorial analysis ANOVA was used to compare treatments (p-value 0.05). d) Leaf sheath assay of $M$. oryzae spores colonising rice leaf cells after $30 \mathrm{~h}$. e) M. oryzae appressorium development under chitosan $\left(5 \mathrm{mg} \mathrm{ml}^{-1}\right)$ on rice leaf surface does not differentiate penetration peg and pathogenicity is inhibited after $30 \mathrm{~h}$. f) $M$. oryzae appressorium development under chitosan $\left(5 \mathrm{mg} \mathrm{ml}^{-1}\right)$ on rice leaf surface with reduced invasive growth compare to controls after $30 \mathrm{~h}$. Bar size $10 \mu \mathrm{m}$.

\section{Figure 2. Chitosan impairs M. oryzae appressorium differentiation concentration-} wise. a) Percentage of $M$. oryzae differentiated appressoria after 4, 6 and $8 \mathrm{~h}$ in contact with (0.5-5 mg ml-1) chitosan. b) Micrographs of $M$. oryzae development after $4 \mathrm{~h}, 6 \mathrm{~h}$ and $8 \mathrm{~h}$ with chitosan $\left(5 \mathrm{mg} \mathrm{ml}^{-1}\right)$ compared with untreated controls. Bar size $10 \mu \mathrm{m}$. c) 
1 Effect of chitosan on $M$. oryzae appressoria area (mean, $\mathrm{n}>20$ ). d) Thickness of appressorium melanin layer differentiated under 1 and $5 \mathrm{mg} \mathrm{ml}^{-1}$ chitosan. Asterisks indicate significant differences. Multifactorial analysis ANOVA was used to compare treatments (p-value $0.05(*))$.

\section{Figure 3. Chitosan prevents septin (SEP4) recruitment and appressorium pore} organisation. a) Micrographs of Sep4-GFP localisation on M. oryzae appressorium development after $8 \mathrm{~h}$ in the presence and absence of chitosan. b) Micrographs of Gelsolin-GFP localisation on $M$. oryzae appressorium development after $8 \mathrm{~h}$ in the presence and absence of chitosan. c) Micrographs of Chm1-GFP localisation on $M$. oryzae appressorium development after $8 \mathrm{~h}$ in the presence and absence of chitosan d) Micrographs of Tea1-GFP localisation on M. oryzae appressorium development after $8 \mathrm{~h}$ in the presence and absence of chitosan. e-h) Linescans of (Sep4), actin (gelsolin), Chm1 and Tea1 protein fusion evaluated with no chitosan show normal ring formation after $8 \mathrm{~h}$. However, linescan of differentiated appressorium under chitosan did not differentiate any ring. Asterisks indicate significant differences (p-values 0.05 (*), 0.01 $(* *), 0.001(* * *)$ and $0.0001(* * * *))$.

Figure 4. Chitosan permeabilises plasma membrane of $M$. oryzae appressorium and induces generation of reactive oxygen species. a) Integrity of plasma membrane on untreated 8h-old appressorium after FM4-64 application. Chitosan severely compromises plasma membrane integrity on appressoria exposed to chitosan; FM4-64 fluorescence shows high intensity within the appressorium. b) Average of FM4-64 fluorescence of chitosan treated appressoria and untreated controls. c) Fluorescence of reduced glutathione by Grx1-roGFP2 on $8 \mathrm{~h}$-old untreated and $5 \mathrm{mg} \mathrm{ml}^{-1}$ chitosan treated appressoria. d) Grx1-roGFP2 fluorescence quantitation in appressoria in the presence and absence of chitosan. e) NADPH oxidases (NOX1 and NOX2) gene expression in Guy 11 exposed for $8 \mathrm{~h}$ and $24 \mathrm{~h}$ to chitosan. Chitosan early (8h) induces NOX2 and represses NOX1 in Guy11. However, after 24h M. oryzae in contact with chitosan, it drastically represses NOX1 and slightly NOX2. Asterisks indicate significant differences (p-values $0.05(*), 0.01(* *)$ and $0.001(* * *))$. 
1 Figure 5. NOXI and CWI pathway are essential for $M$. oryzae sensitivity to

2 chitosan.

3

a) Mycelium from Guy11, $\Delta$ nox1, $\Delta$ nox2, and $\Delta$ noxlnox2 mutants was inoculated onto complete medium containing chitosan at a concentration 0.5 and $1 \mathrm{mg} \mathrm{ml}^{-1}$ and incubated at $24^{\circ} \mathrm{C}$ for $2 \mathrm{~d}$ with a $12 \mathrm{~h}$ light/dark cycle. b) $\Delta$ noxl, but specially $\Delta$ noxlnox2, show high tolerance for growing with chitosan in CM medium indicating the key role of $\Delta$ noxl in sensitivity of $M$. oryzae to chitosan. $\Delta m p s 1$ is also able to grow under high doses of chitosan indicating. c) Guy 11 and $P k c^{A S}$ in absence of NAPP1 showed a significant decrease of biomass growing with chitosan respect to untreated control. However, when $P k c^{A S}$ is growing with chitosan and NA-PP1 is added in the media, this strain showed increased tolerance to chitosan. d) Guy 11 mycelium grown in the presence of chitosan was more resistant to cell wall degrading enzymes, showing significantly less protoplast release. e) Guy11 show less amount of chitin in its cell wall than $\triangle$ noxl indicating the key role of $N O X I$ in the cell wall biosynthesis. Chitosan propitiates in both Guy11and $\Delta$ noxl a significantly reduced amount of chitin in their cell walls. f) Guylland $\Delta$ noxl shows similar amount of glucan in their cell walls. However, exposure of these strains to chitosan increases glucan content in Guy 11 , and to a less extent in $\Delta$ noxl g) Micrograph of Nox1-GFP localisation on M. oryzae appressorium development after $8 \mathrm{~h}$ en the presence and absence of chitosan. Multifactorial analysis ANOVA was used to compare treatments (p-values $0.05(*)$, $0.01(* *), 0.001(* * *)$ and $0.0001(* * * *))$.

Figure 6. Chitosan represses $P K C 1$ pathway through $N O X 1$ activity. Exposure of Guy 11 to chitosan for $8 \mathrm{~h}$ and $24 \mathrm{~h}$ propitiates $P K C 1, M P S 1$, SWI6 and $R H O 1$ repression through NOX1 activity. $\Delta$ noxl show overexpression of the main CWI pathway genes (PKC1, MPS1, SWI6 and RHO1) after 8h. This would indicate that NOX1 acts by repressing $M$. oryzae CWI pathway gene expression in response to chitosan. Multifactorial analysis ANOVA was used to compare treatments (p-values $0.05(*)$, $0.01(* *), 0.001(* * *)$ and $0.0001(* * * *))$. 
bioRxiv preprint doi: https://doi.org/10.1101/2020.05.15.098657; this version posted May 16, 2020. The copyright holder for this preprint

(which was not certified by peer review) is the author/funder, who has granted bioRxiv a license to display the preprint in perpetuity. It is made available under aCC-BY-NC 4.0 International license.

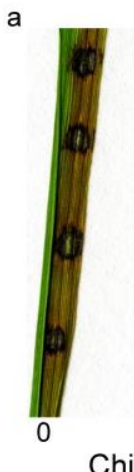

Chitosan $\left(\mathrm{mg} \mathrm{ml}^{-1}\right)$

d

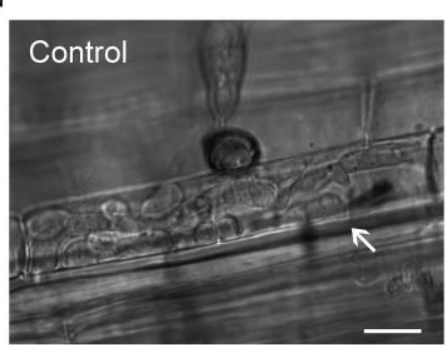

b

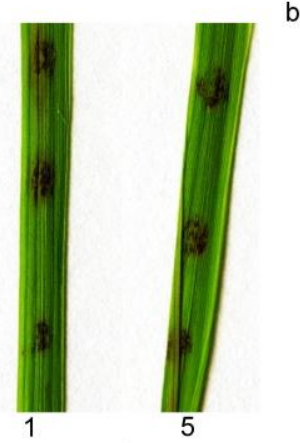

e

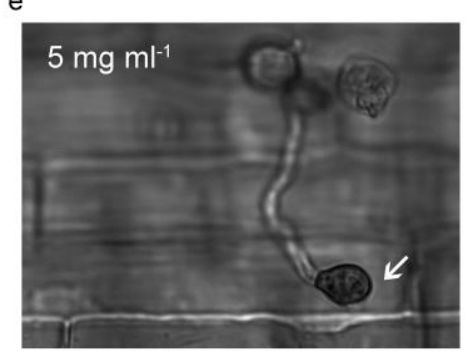

C
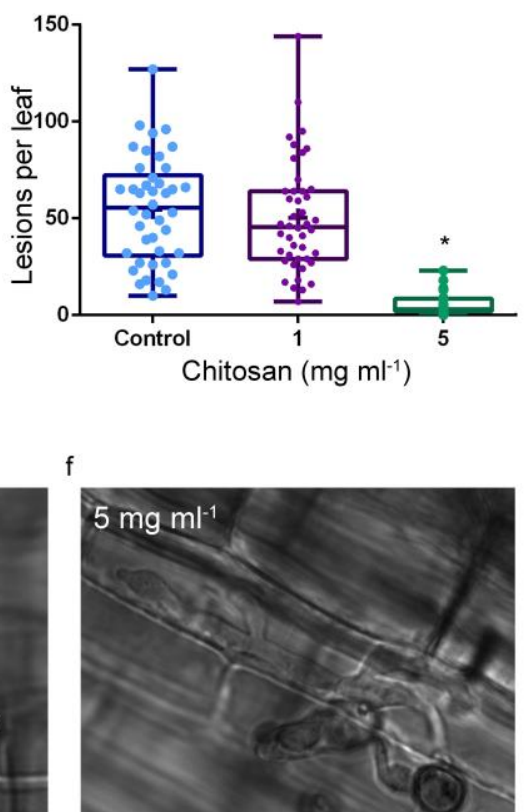

2 Figure 1

3

4 
bioRxiv preprint doi: https://doi.org/10.1101/2020.05.15.098657; this version posted May 16, 2020. The copyright holder for this preprint

(which was not certified by peer review) is the author/funder, who has granted bioRxiv a license to display the preprint in perpetuity. It is made available under aCC-BY-NC 4.0 International license.
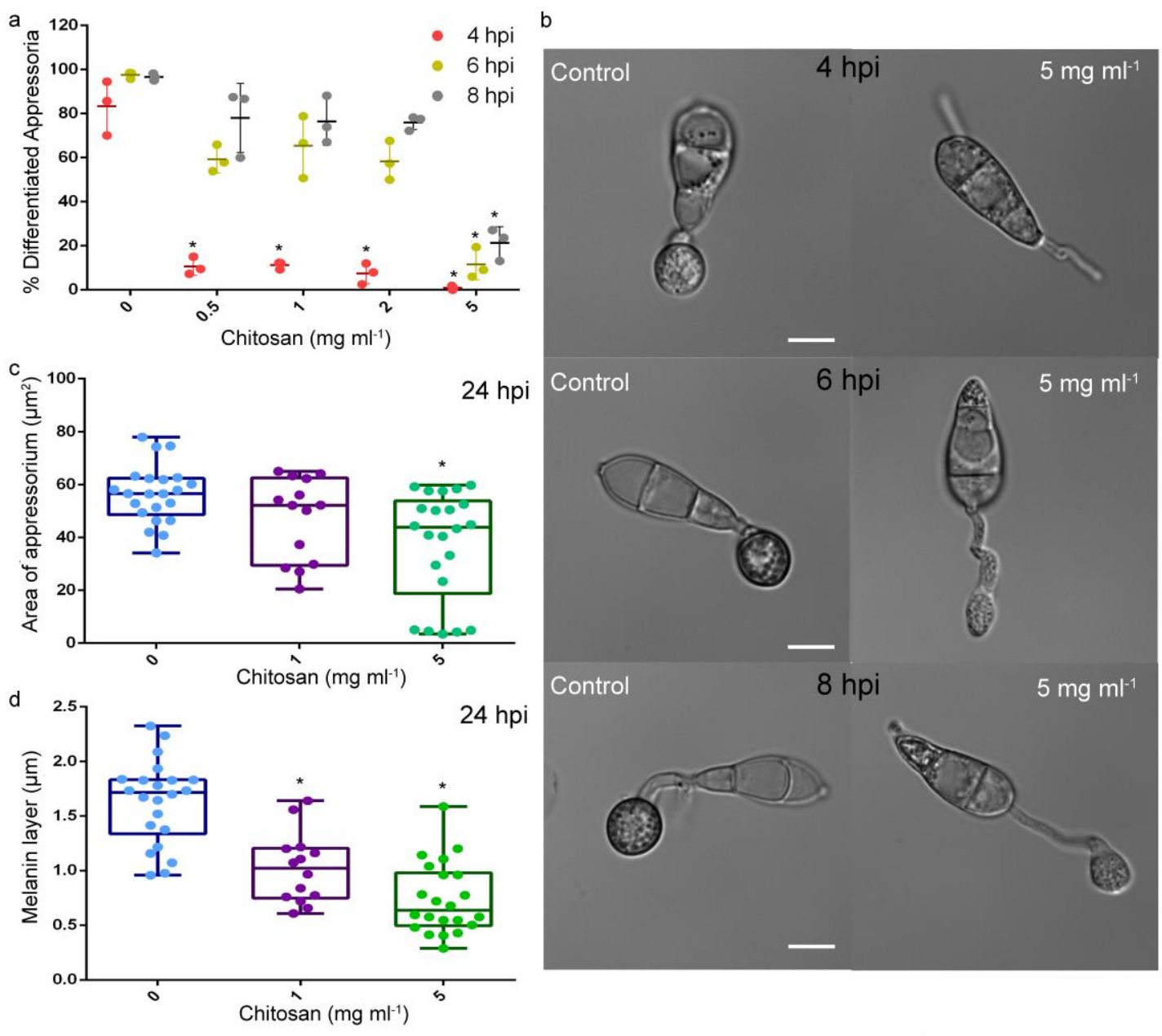

2 Figure 2 
bioRxiv preprint doi: https://doi.org/10.1101/2020.05.15.098657; this version posted May 16, 2020. The copyright holder for this preprint (which was not certified by peer review) is the author/funder, who has granted bioRxiv a license to display the preprint in perpetuity. It is made available under aCC-BY-NC 4.0 International license.
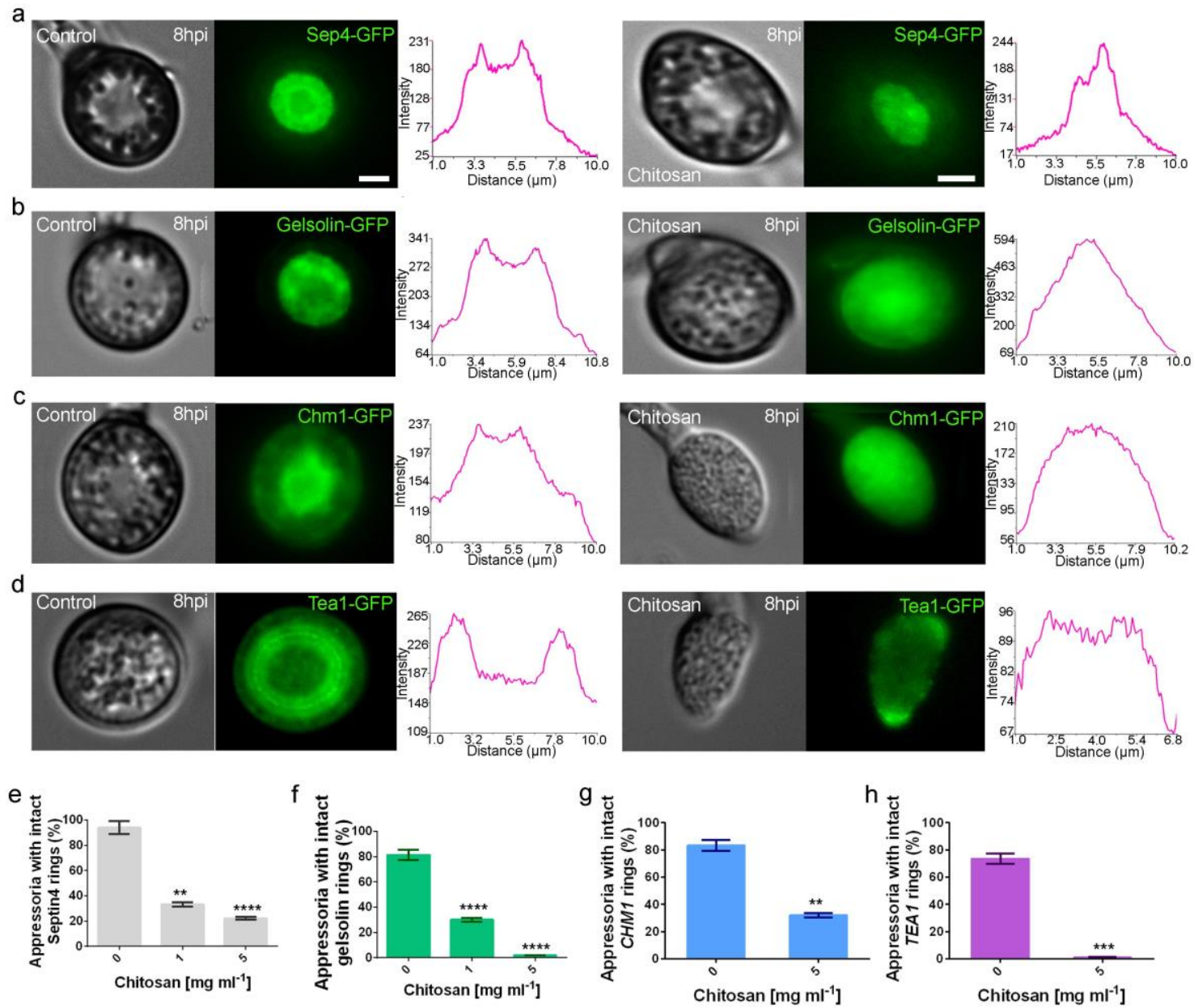

Figure 3 
bioRxiv preprint doi: https://doi.org/10.1101/2020.05.15.098657; this version posted May 16, 2020. The copyright holder for this preprint

(which was not certified by peer review) is the author/funder, who has granted bioRxiv a license to display the preprint in perpetuity. It is made available under aCC-BY-NC 4.0 International license.

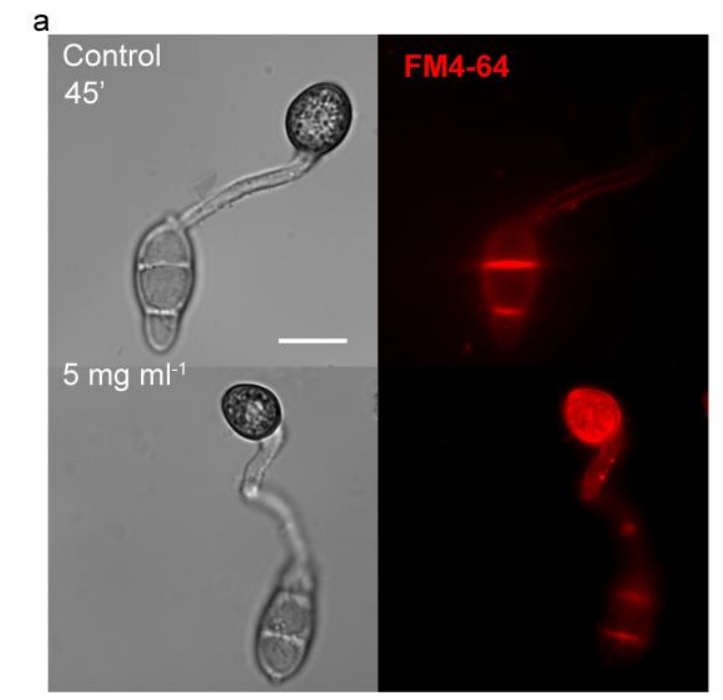

b

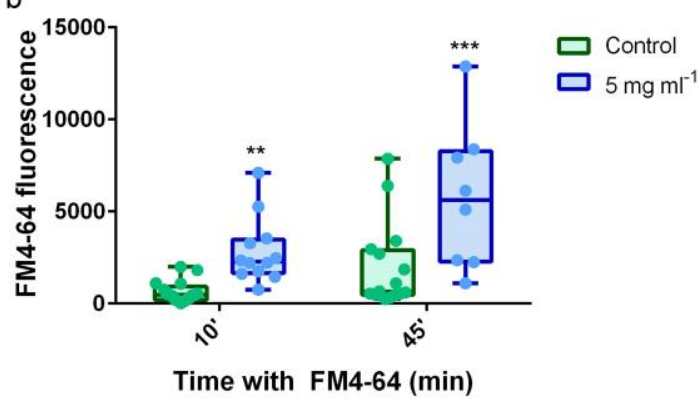

C

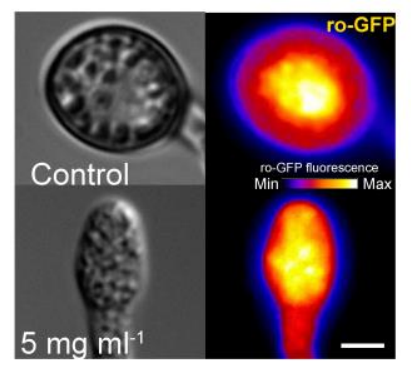

d

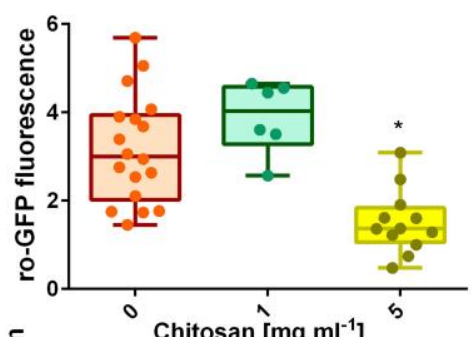

e

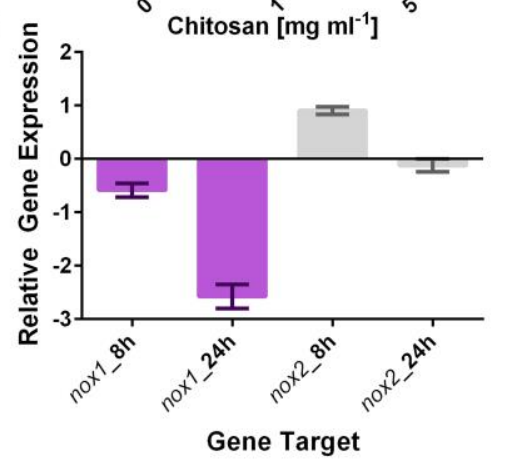

2 Figure 4 
bioRxiv preprint doi: https://doi.org/10.1101/2020.05.15.098657; this version posted May 16, 2020. The copyright holder for this preprint

(which was not certified by peer review) is the author/funder, who has granted bioRxiv a license to display the preprint in perpetuity. It is made available under aCC-BY-NC 4.0 International license.
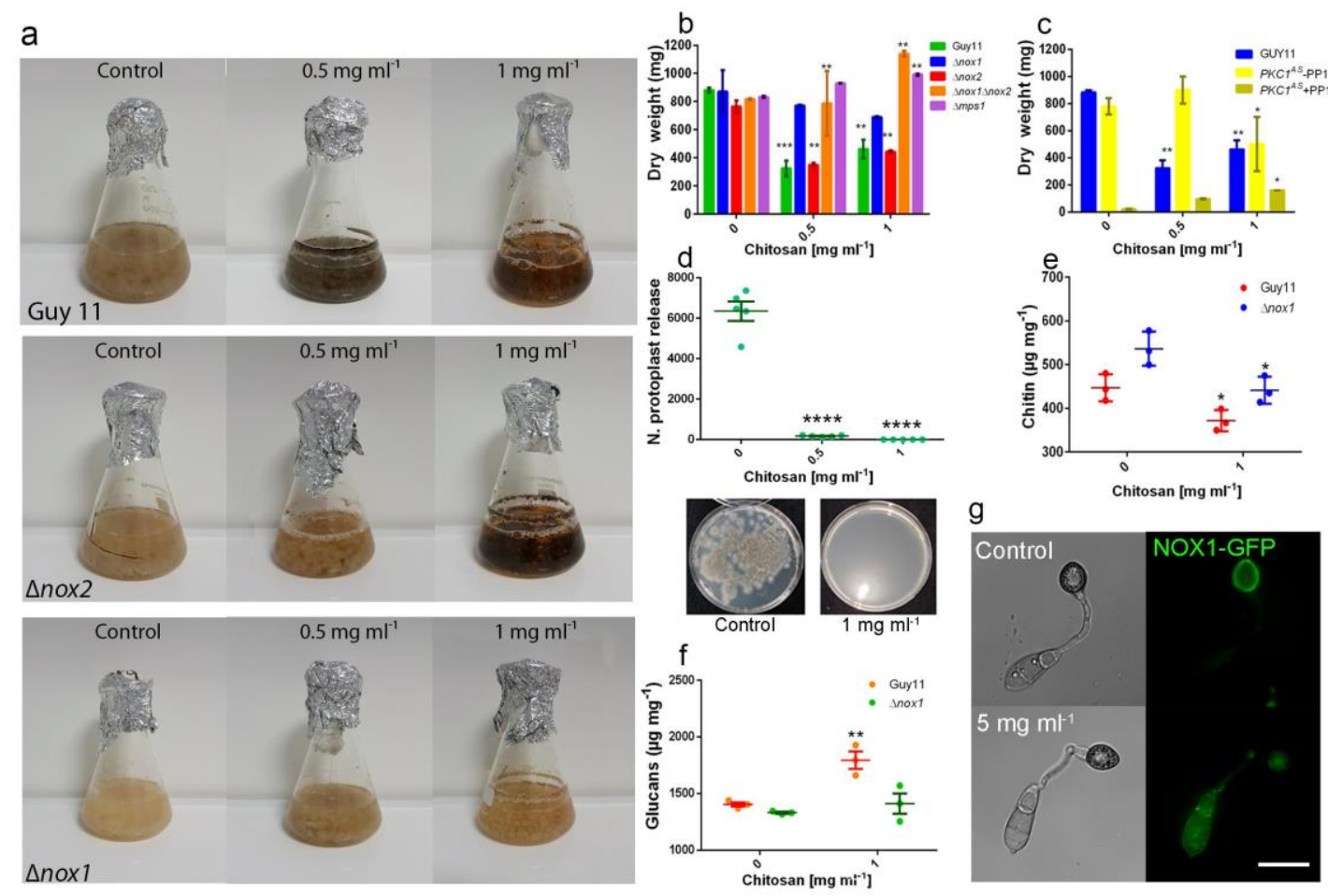

Figure 5 
bioRxiv preprint doi: https://doi.org/10.1101/2020.05.15.098657; this version posted May 16, 2020. The copyright holder for this preprint

(which was not certified by peer review) is the author/funder, who has granted bioRxiv a license to display the preprint in perpetuity. It is made available under aCC-BY-NC 4.0 International license.
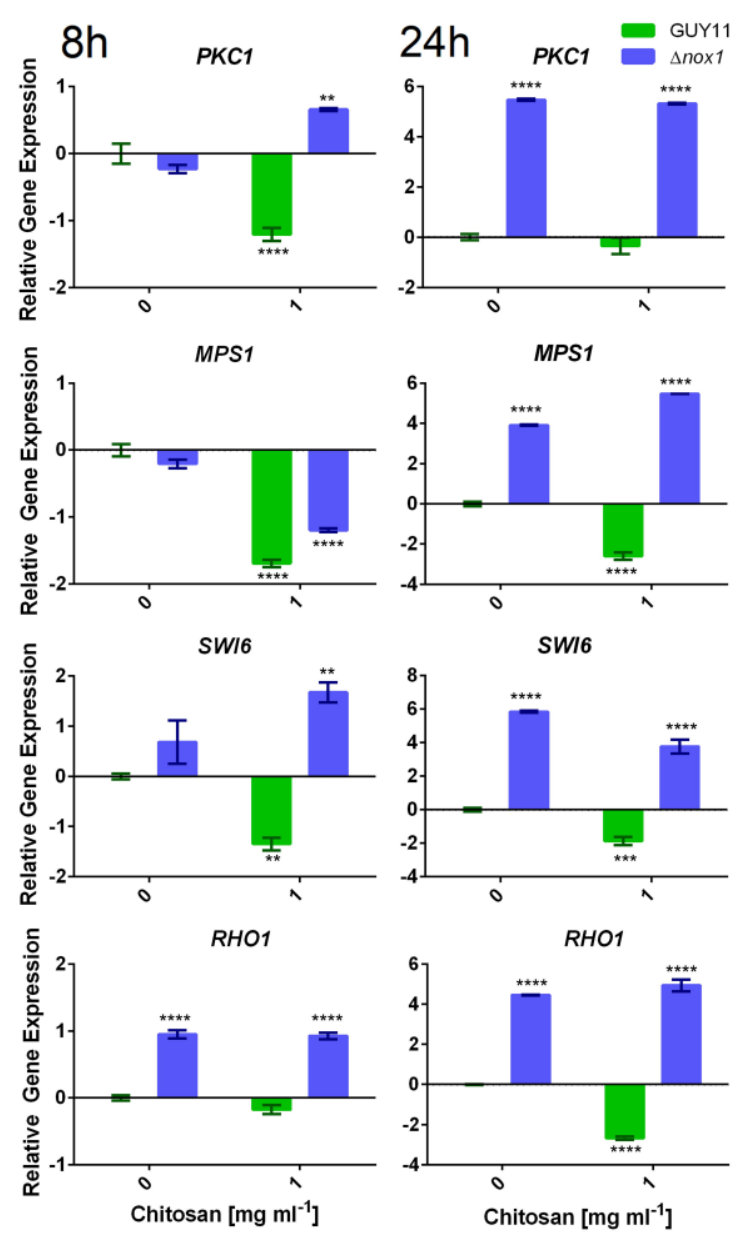

2 Figure 6 